\title{
Formulation and Optimization of Carbamazepine Microspheres by 2 Factor 2 Level Central Composite Design
}

\author{
Nusrat Ahmed', Ikramul Hasan', Mohammad Saifuddin², Jakir Ahmed Chowdhury ${ }^{1}$ \\ and Md. Selim Reza ${ }^{1}$
}

${ }^{1}$ Department of Pharmaceutical Technology, Faculty of Pharmacy, University of Dhaka, Dhaka-1000, Bangladesh ${ }^{2}$ Department of Business Administration, Bangladesh University, 15/1, Iqbal Road, Mohammadpur, Dhaka-1207, Bangladesh

Received: April 14, 2016; Accepted: May20, 2016; Published (Web): July 31, 2016

\begin{abstract}
The present investigation was designed to prepare controlled release microspheres of carbamazepine using two polymers of different solubility and permeability characteristics, Ethocel standard 45 premium and Eudragit RL 100. The drug release profile was optimized with the aid of design of experiments (DoE). Microspheres of combined polymers were designed according to $2^{2}$ factorial central composite design (CCD), taking drug loading and polymeric ratio as the independent variables. Total thirteen batches were prepared. The dependent variables were percentage of drug released in 3 hours and 6 hours and mean dissolution time (MDT). The regression parameters of the developed model and graphical interpretation for each response with statistical significance were calculated by using Minitab 17. The relationship between the experimental variables and responses were evaluated by generating response surface plots. Increased amount of Eudragit RL 100 had impact on surface morphology of prepared microspheres. It produced larger holes on the surface due to its higher permeability characteristics. Polynomial mathematical models generated for various response variables using multiple linear regression analysis, were found to be statistically significant ( $<<0.05$ ). One optimum formulation (O1) was selected based on USP specification and the second optimum formulation (O2) was selected for the maximization of MDT (hours). Batch O1 showed $22.85 \%$ and $48.78 \%$ drug release after 3 and 6 hours, respectively which were found to be in close agreement with those predicted by the mathematical model. Another optimum formulation, batch O2 showed MDT as 160.61 hours.
\end{abstract}

Key words: DoE, optimization, Eudragit RL100, carbamazepine, microsphere

\section{Introduction}

Statistical modeling and experimental design are two most essential tools in the field of formulation development (Montgomery and Douglas, 2012; Singh et al., 2011). While developing a sustained release microsphere dosage form, an important issue is to design an optimized formulation with an ideal release profile in a specific time period and minimum number of trials. For this purpose, in this current study formulations of microspheres are developed with response surface methodology (RSM) utilizing a polynomial equation (Mandal et al., 2007; Singh et al., 2006). Carbamazepine, a BCS Class II drug was chosen as a model drug because it shows poor water solubility and erratic oral absorption property. Peak plasma concentration of the conventional carbamazepine tablets varies from 4 to 8 hours but may be delayed up to 24 hours (Katzung et al., 2015; Goodman et al., 2006). Carbamazepine is also characterized by shorter biological half-life ( 12 hours) during chronic dosing, due to auto-induction of hepatic metabolism and it may fall approximately to 8 hours in patients receiving other enzyme-inducing drugs (Katzhendler et al., 1998; Filipović-Grčić et al., 2003). The rate and extent of absorption and thus bioavailability of carbamazepine can be increased by enhancing dissolution profile of the drug. Various attempts were taken by several investigators to enhance rate of dissolution of

Correspondence to: Md. Selim Reza; Tel: 880-2-9672733, Ext. 8175; Fax: 880-2-9667222; E-mail: selimreza@du.ac.bd 
carbamazepine (Filipović-Grčić et al., 2003; Gavini et al., 2006; Moneghini et al., 2001; Javadzadeh et al., 2007; Passerini et al., 2002). Among these it was reported that spray drying technique enhanced the rate of dissolution of carbamazepine because of reduction in crystallinity of carbamazepine (Filipović-Grčić et al., 2003). Another issue is an immediate release formulation of carbamazepine shows various central nervous system side effects (Olling et al., 1999).

Thus the present investigation was designed to prepare controlled release microspheres of carbamazepine using two polymers of different solubility and permeability characteristics, Ethocel standard 45 premium and Eudragit RL 100 (Haznedar and Dortunç, 2004; Kusum Devi et al., 2003). Emulsion solvent evaporation was the choice of technique. The drug release profile was optimized with the aid of design of experiments (DoE). The microspheres of combined polymers were designed according to $2^{2}$ factorial central composite design (CCD), taking drug loading and polymeric ratio as the independent variables. Total thirteen batches were prepared. The dependent variables selected were percentage of drug released in 3 hours, percentage of drug released in 6 hours and MDT. Because in USP for extended release formulations of carbamazepine specifications were made for percentage of drug release after 3 hours and 6 hours. The percentage of amount dissolved should be between $10 \%$ to $35 \%$ and $35 \%$ to $65 \%$ after 3 hours and 6 hours, respectively (USP 29, 2007).

\section{Materials and Methods}

Carbamazepine was obtained as a generous gift from Beximco Pharmaceuticals Ltd. Ethocel standard 45 premium (Colorcon Asia Pvt. Ltd, USA), Eudragit
RL 100 (Evonik Industries, Germany), liquid paraffin (Merck, Germany), Span 80 (Merck, Germany), acetone (Merck, Germany), n-hexane (Merck, Germany) were obtained from the mentioned sources. Sodium lauryl sulfate was purchased from local market.

Preparation of carbamazepine microspheres: The method of preparation of carbamazepine microspheres was based on emulsion solvent evaporation method using two different polymers: Ethocel standard 45 premium and Eudragit RL 100 (Rajkumar and Bhise, 2010; Behera et al., 2008). Weighed quantities of both polymers and carbamazepine were dissolved in acetone at room temperature. This solution of internal phase was then slowly poured drop by drop to the liquid paraffin which was previously emulsified with $1 \%$ span 80 at same temperature. The whole system was stirred continuously at $1000 \mathrm{rpm}$ for 3 hours. After that the microspheres were separated by filtration. Thereafter, the excess paraffin oil retained in the surface of microspheres was eliminated by repeated washing (4 to 5 times) with n-hexane and finally dried and preserved in a desiccator. The dried microspheres were stored in a glass vial after proper identification.

Experimental design: The microspheres of combined polymers are designed according to $2^{2}$ factorial central composite design (CCD) (Bezerra et al., 2008). Drug loading (\%) and the polymeric ratio of Ethocel standard 45 premium \& Eudragit RL 100 were the two independent variables. The selected variables with the actual and coded levels as per the design are represented in Table 1. The higher, lower and the intermediate levels of each variable are coded as $+1,-1$ and 0 respectively. Final formulation of all batches with their respective amounts is represented in Table 2.

Table 1. Formulation protocol for the microspheres designed by $2^{2}$ factorial CCD.

\begin{tabular}{llllcccc}
\hline & \multicolumn{7}{c}{ Coded level } \\
\hline Variables & Code & Units & $-\alpha$ & -1 & 0 & +1 & $+\alpha$ \\
\hline Drug loading & $\mathrm{X} 1$ & $\%$ & 0.2379 & 0.30 & 0.45 & 0.60 & 0.6621 \\
Polymer ratio & $\mathrm{X} 2$ & - & 0.1895 & 0.50 & 1.25 & 2.00 & 2.3105 \\
\hline
\end{tabular}


Table 2. Composition of different microspheres formulations.

\begin{tabular}{|c|c|c|c|c|c|c|c|}
\hline \multirow{2}{*}{$\begin{array}{c}\text { Formulat } \\
\text { ion } \\
\text { code }\end{array}$} & \multicolumn{2}{|c|}{ Coded variables } & \multicolumn{2}{|c|}{ Independent variables } & \multirow{2}{*}{$\begin{array}{c}\text { Carbamazepin } \\
\text { e (gm) }\end{array}$} & \multirow{2}{*}{$\begin{array}{c}\text { Ethocel Std. } \\
45 \text { P (gm) }\end{array}$} & \multirow{2}{*}{$\begin{array}{c}\text { Eudragit RI } \\
100(\mathrm{gm})\end{array}$} \\
\hline & $\mathrm{X} 1$ & $\mathrm{X} 2$ & $\begin{array}{c}\text { Drug loading } \\
(\%)\end{array}$ & $\begin{array}{l}\text { Ethocel Std } 45 \text { P: } \\
\text { Eudragit RL } 100\end{array}$ & & & \\
\hline B1 & 1 & 1 & 60 & $2: 1$ & 0.6 & 0.266 & 0.133 \\
\hline $\mathrm{B} 2$ & 1 & -1 & 60 & $1: 2$ & 0.6 & 0.133 & 0.266 \\
\hline B3 & -1 & 1 & 30 & $2: 1$ & 0.3 & 0.466 & 0.233 \\
\hline B4 & -1 & -1 & 30 & $1: 2$ & 0.3 & 0.233 & 0.466 \\
\hline B5 & -1.414 & 0 & 23.79 & $1.25: 1$ & 0.2379 & 0.423 & 0.339 \\
\hline B6 & 1.414 & 0 & 66.21 & $1.25: 1$ & 0.6621 & 0.188 & 0.150 \\
\hline B7 & 0 & -1.414 & 45 & $0.1895: 1$ & 0.45 & 0.088 & 0.462 \\
\hline B8 & 0 & 1.414 & 45 & $2.3105: 1$ & 0.45 & 0.384 & 0.166 \\
\hline B9 & 0 & 0 & 45 & $1.25: 1$ & 0.45 & 0.306 & 0.244 \\
\hline B10 & 0 & 0 & 45 & $1.25: 1$ & 0.45 & 0.306 & 0.244 \\
\hline B11 & 0 & 0 & 45 & $1.25: 1$ & 0.45 & 0.306 & 0.244 \\
\hline B12 & 0 & 0 & 45 & $1.25: 1$ & 0.45 & 0.306 & 0.244 \\
\hline B13 & 0 & 0 & 45 & $1.25: 1$ & 0.45 & 0.306 & 0.244 \\
\hline
\end{tabular}

Variable X1 represents drug loading (\%) and variable X2 represents ratio of the polymers, Ethocel standard 45 premium and Eudragit RL 100.

Morphology study by scanning electron microscope (SEM): Microspheres were observed by Scanning Electron Microscopy (SEM) to see the morphological changes that occurred due to the formulation variation. The microsphere from the selected batches were mounted on the SEM sample stab (aluminium stabs) which were coated with a double sided sticking tape, sealed and finally coated with gold $\left(200 \mathrm{~A}^{\circ}\right)$ under reduced pressure (0.001 torr) for 15 minutes using ion sputtering device. The gold coated samples were scanned using scanning electron microscope (s-3400N, Hitachi) under different magnification.

In vitro dissolution study of carbamazepine microspheres: The dissolution studies of the microspheres were carried out in a basket type (type II) USP dissolution apparatus. Weighed amount $(50 \mathrm{mg})$ of microspheres were taken in $900 \mathrm{~mL}$ of dissolution medium (distilled water containing $1 \%$ sodium lauryl sulfate) and were stirred at $100 \mathrm{rpm}$ at $37 \pm 0.5^{\circ} \mathrm{C}$ (USP 29, 2007). A $10 \mathrm{~mL}$ dissolution sample was withdrawn from the dissolution medium at pre-determined intervals of 30 minute, $1^{\text {st }}$ hour, $2^{\text {nd }}$ hour, $3^{\text {rd }}$ hour, $4^{\text {th }}$ hour, $5^{\text {th }}$ hour, $6^{\text {th }}$ hour, $7^{\text {th }}$ hour $\& 8^{\text {th }}$ hour. Collected samples were analyzed spectrophotometrically through an UV spectrophotometer at $284 \mathrm{~nm}$ after suitable dilution to determine the amount of the drug released from the microspheres. The percentage of drug release was plotted versus time. The dissolution study was repeated three times for each batch.

ANOVA and response surface analysis: Analysis of variance and response surface analysis was conducted for cumulative percent of drug released after 3 hours \& 6 hours and MDT using Minitab 17.

\section{Results and Discussion}

Observation of microspheres by scanning electron microscope (SEM): SEM images of the batches prepared with drug load variation and polymer ratio variation were taken and were analyzed morphologically.

Here, batch B1 is the microsphere of carbamazepine using Ethocel standard 45 premium and Eudragit RL 100 at the ratio of 2:1 having $60 \%$ drug loading. As shown in SEM photographs Figure 1, the microspheres were spherical, smoother and less porous in nature. Batch B2 is the microsphere of carbamazepine using Ethocel standard 45 premium and Eudragit RL 100 at the ratio of 1:2 having $60 \%$ drug loading. SEM image revealed that microspheres were spherical, smoother and had large holes on the surface.

Eudragit RL 100 has quaternary ammonium group in the structure, which increases its solubility characteristics (Sonje and Chandra, 2013). Comparing 
SEM images of B1 and B2 it can be concluded that as the amount of Eudragit RL 100 was more in batch B2, it produced larger holes on the surface due to its higher permeability characteristics. These larger holes may further ensure higher drug release profile in the body
(USP 29, 2007). It is confirmed in the cumulative percent drug release data obtained from dissolution studies as illustrated in "Results and Discussion" section.

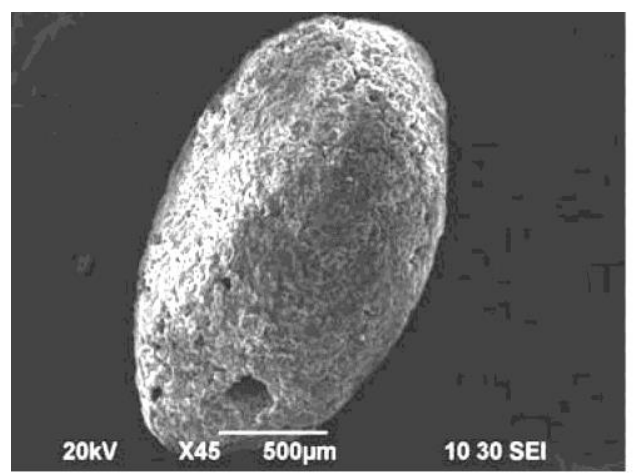

SEM image of B1

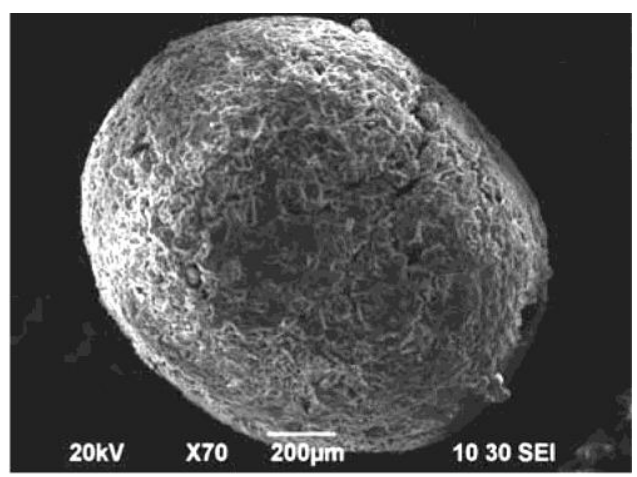

SEM image of B2

Figure 1. Effect of Ethocel standard 45 premium and Eudragit RL 100 on the surface morphology on batch B1, B2 and B3.

In vitro dissolution and kinetic studies of carbamazepine microspheres: Figure 2 represents the release of carbamazepine from microspheres in different drug: polymer ratio. The rate of drug release from the microspheres depended on the amount of polymer and the type of polymer used (Mukhopadhyay et al., 2014). As concentration of Ethocel standard 45 premium increased the release rate was decreased which may be due to increase in thickness of polymer matrix layer (Mane et al., 2013). The decrease in release rate with increasing content of the Ethocel can also be explained by the fact that the amount of uncoated drug decreases with the increase of Ethocel amount and drug diffusion becomes more retarded (Filipović-Grčić et al., 2003; Mukhopadhyay et al., 2014). As compare to Ethocel, microspheres having more amount of Eudragit RL 100 showed a little higher drug release rate, which is attributed to the difference in the permeability characteristics (USP 29, 2007).

The results of in vitro dissolution studies have shown that batches B2 and B6 had higher drug release profile. Comparing the formulation of batches B2 and B6 it was observed that as the drug loading increases, percent release of drugs also increases accordingly (Filipović-Grčić et al., 2003). Batch B2 showed 72.82 $\%$ cumulative drug release at the end of 8 hours and batch B6 showed $70.43 \%$ cumulative drug release at the end of 8 hours. Although batch B2 had $60 \%$ drug loading compared to batch B6 which had $66.21 \%$ drug loading but B2 showed little bit higher drug release profile than B6. Because it had relatively higher amount of Eudragit RL 100 in the composition.

Statistical analysis and model development: The regression parameters of the developed model and graphical interpretation for each response with statistical significance were calculated by using Minitab 17. The relationship between the experimental variables and responses were evaluated by generating response surface plots (Myers et al., 2016).

The quadratic model was selected by the software for both the responses. Multiple regression analysis was used to correlate the responses of percentage drug release and MDT with the two variables studied using a second order polynomial equation. The quadratic regression models for cumulative percentage of drug release after 3 hours (Y1), Cumulative percentage of drug release after 6 hours (Y2) and MDT can be represented by following equations of (1), (2) and (3):

$\mathrm{Y} 1(3$ hours $)=48.47+4.88 \mathrm{~A}-7.31 \mathrm{~B}-9.33 \mathrm{~A}^{2}-$ $5.24 \mathrm{~B}^{2}+1.19 \mathrm{AB}$

$\mathrm{Y} 2(6$ hours $)=58.33+7.49 \mathrm{~A}-9.36 \mathrm{~B}-8.46 \mathrm{~A}^{2}$ $-4.83 \mathrm{~B}^{2}+1.06 \mathrm{AB}$ 
MDT (hours) $=7.35-18.55 \mathrm{~A}+19.17 \mathrm{~B}+14.36 \mathrm{~A}^{2}$ $+9.38 \mathrm{~B}^{2}-19.28 \mathrm{AB}$

Here, in Eq. (1), (2) and (3), A and B represents the coded values for X1 and X2.

\section{Statistical significance of the model}

Effect of formulation variables on percent release at the end of 3 hours (Yl): The adequacy and significance of the model was justified by analysis of

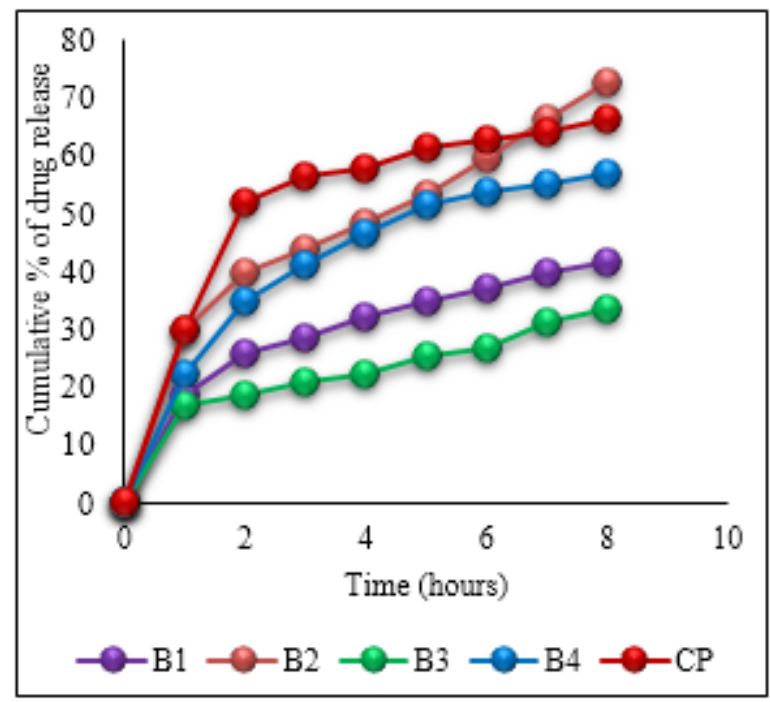

variance (ANOVA). Analysis of the acquired data shows that the $\mathrm{F}$ value of the model is 17.75 , which is significant. The F-value of the model has P-value 0.001 $<0.05$ (significance level) which indicates that the overall model has significant capacity to explain variation in response variable $\mathrm{Y} 1$ ( 3 hours). At $5 \%$ significance level, a model is considered significant if the $\mathrm{P}$ value (significance probability value) is less than 0.05 .
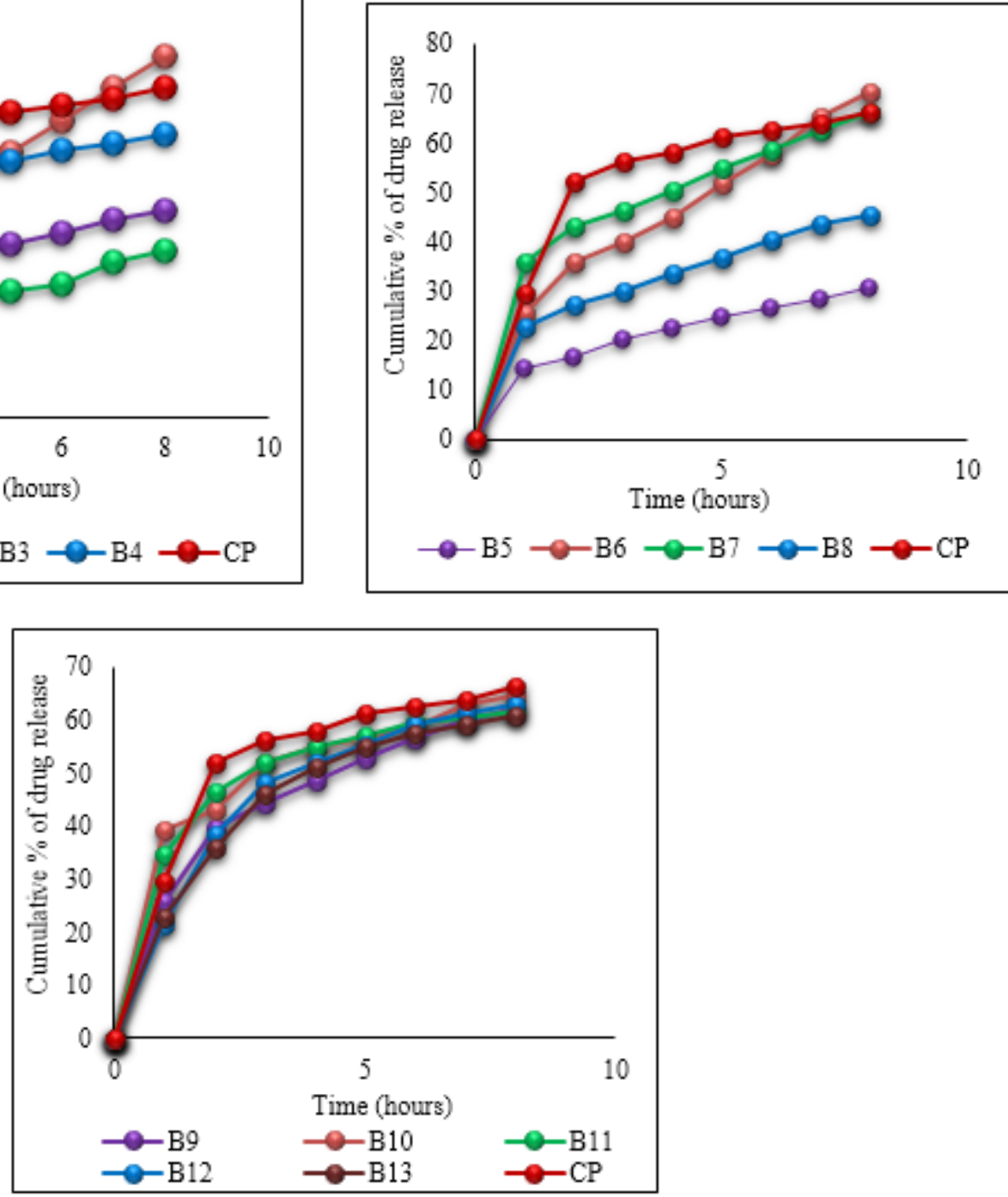

Figure 2. Cumulative percent drug release vs time curves.

However, both linear (effects of A and B) and quadratic effects (effects of $\mathrm{A}^{2}$ and $\mathrm{B}^{2}$ ) are also significant. But interaction effect (effect of $A B$ ) is not significant. Insignificant lack of fit also reflects the model adequacy. After all, the $\mathrm{R}^{2}=92.69 \%$ implies that the model can explain $92.69 \%$ variation in $\mathrm{Y} 1$.

The response surface plot revealed that the drug loading and polymer ratio had a significant opposing 
impact on the drug release without creating any interaction effect. The surface plot (Figure 3) shows that highest yield (Y1) obtained when X1 level (drug loading) is high and $\mathrm{X} 2$ level (polymer ratio) is low. Drug release at the end of 3 hours increased from 20.52 $\%$ to $32.66 \%$ and from $37.52 \%$ to $44.90 \%$ at high and low levels of polymer ratio (Ethocel standard 45 premium: Eudragit RL 100) respectively as the drug loading increased. That indicates when the amount of Ethocel standard 45 premium was comparatively high it showed greater release retarding property due to its hydrophobic nature (Jain et al., 2010; Shivakumar et al., 2008).

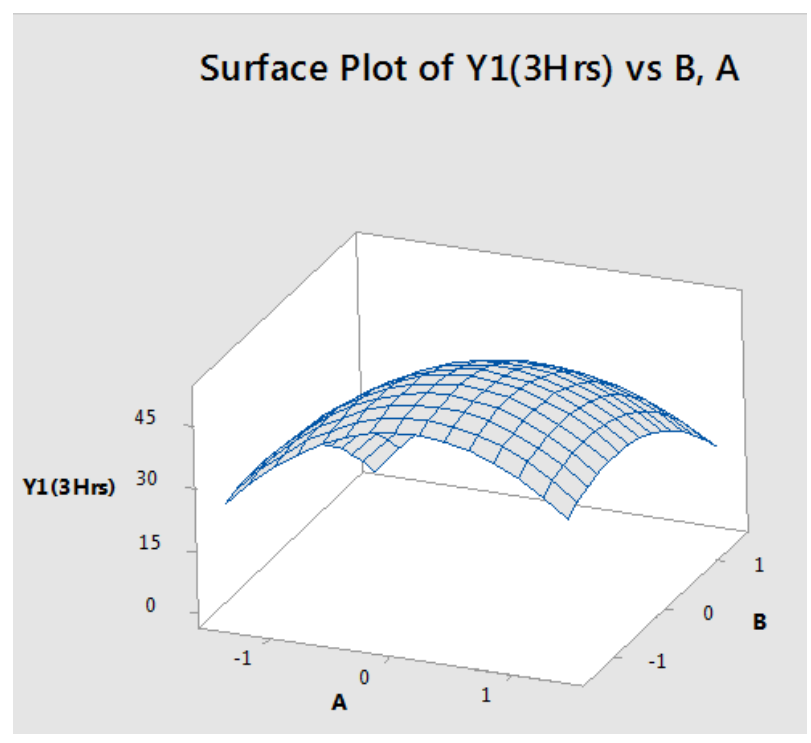

Figure 3. Response surface plot showing the effect of formulation variables on percent release at the end of 3 hours.

The surface plot (Figure 4) shows that highest yield (Y2) obtained when X1 level (drug loading) is high and $\mathrm{X} 2$ level (polymer ratio) is low. The 3D plot shows that the drug release at the end of 6 hours increased from $27.13 \%$ to $44.23 \%$ and from $47.97 \%$ to $60.83 \%$ at lower and higher levels of polymer ratio (Ethocel standard 45 premium: Eudragit RL 100) respectively as the drug loading levels increased. Eudragit RL 100 has greater permeability characteristic because of having greater quaternary ammonium group content in the polymer. This specific property can explain the
Effect of formulation variables on percent release at the end of 6 hours (Y2): The analysis of variance of the regression model explains that the model is highly significant, as is evident from the F-value (13.85). The $\mathrm{P}$ value of $<0.05$ was considered statistically significant. However, both linear (effects of A and B) and quadratic effects (effects of $\mathrm{A}^{2}$ and $\mathrm{B}^{2}$ ) are also significant. Lack of fit was not significant for the model. After all, the $\mathrm{R}^{2}=90.82 \%$ implies that the model can explain $90.89 \%$ variation in $\mathrm{Y} 2$.

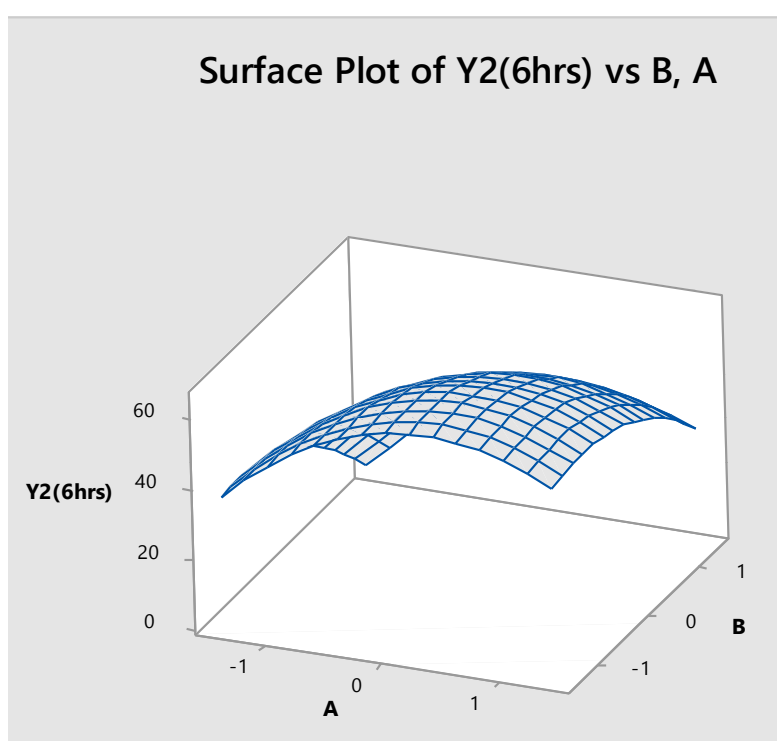

Figure 4. Response surface plot showing the effect of formulation variables on percent release at the end of 6 hours.

enhancement in percent drug release with comparative increase in Eudragit RL 100 amount.

Effect of formulation variables on MDT (hours): ANOVA data shows that the F-Value (10.12) of the model has P-value $0.004<0.05$ (significance level) which indicates that the overall model has significant capacity to explain variation in response variable MDT (hours). Linear (effects of A and B) effects are significant but quadratic effects (effects of $\mathrm{B}^{2}$ ) are not significant. Interaction effect (effect of $\mathrm{AB}$ ) is significant. After all, the $\mathrm{R}^{2}=87.85 \%$ implies that the model can explain $87.85 \%$ variation in MDT. 


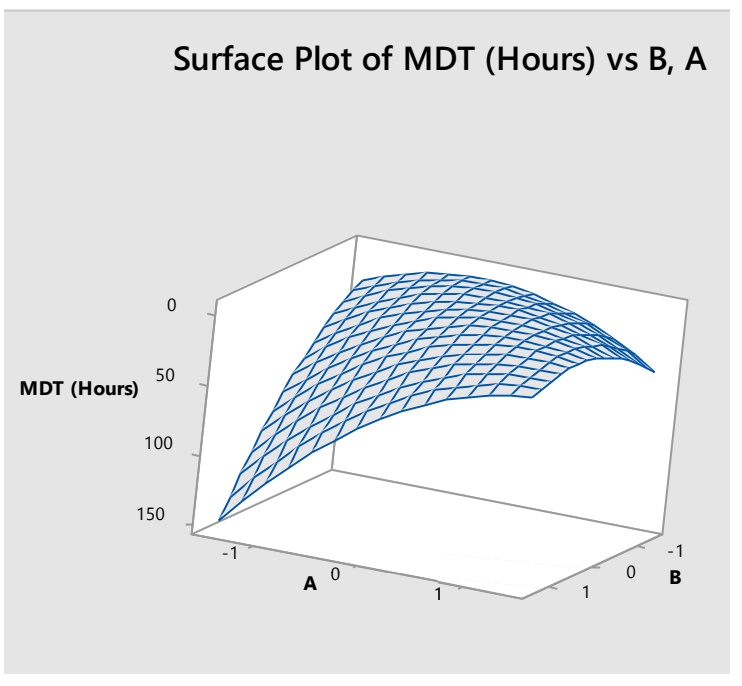

Figure 5. Response surface plot showing the effect of formulation variables on MDT.

The surface plot (Figure 5) shows that highest yield (MDT) obtained when X1 level (drug loading) is low and $\mathrm{X} 2$ level (polymer ratio) is high. The 3D plot shows that the MDT increased from 12.65 hours to 88.09 hours at lower and higher levels of polymer ratio (Ethocel standard 45 premium: Eudragit RL 100) respectively as the drug loading levels decreased.

\section{Response optimization}

Response optimization results for $Y 1$ and $Y 2$ :

Parameters

\begin{tabular}{ccccc}
\hline Response & Goal & Lower & Target & Upper \\
\hline Y2 (6 hrs) & Target & $35 \%$ & $\mathbf{5 0 . 0} \%$ & $65 \%$ \\
Y1 (3 hrs) & Target & $10 \%$ & $\mathbf{2 2 . 5} \%$ & $35 \%$ \\
\hline
\end{tabular}

Response optimization results for MDT (hours):

The optimization of the responses was conducted with the help of Minitab 17 software, which was used to construct the response surface plot for the fitted polynomial equations and to find the optimum area, at which the desired responses could be achieved. One optimum formulation (O1) was selected based on the following criteria: Y1 (percentage drug released at the end of 3 hours of dissolution) should be $22.5 \%$ and Y2 (percentage drug released at the end of 6 hours of dissolution) should be $50 \%$. And the second optimum formulation $(\mathrm{O} 2)$ was selected for the maximization of MDT (hours). The first formulation showed $\mathrm{Y} 1$ as $22.85 \%$ and Y2 as $48.78 \%$ (Table 3). Another optimum formulation (O2) showed MDT (hours) as 160.61 hours (Table 4).

For the optimum formulation, the results of the $\mathrm{Y} 1$ (percentage drug released at the end of 3 hours of dissolution) and Y2 (percentage drug released at the end of 6 hours of dissolution) were found to be in close agreement with those predicted by the mathematical model. Table 4 lists the compositions of the checkpoints, their predicted and experimental values of all the response variables, and the percentage error. Figure 6 shows linear correlation plots between the observed and predicted response variables. When observed responses were compared with that of the predicted responses, we found that the prediction error varied between $1.55 \%$ and $2.45 \%$. As the prediction error for the response parameters was low, it establishes the high forecasting ability of response surface methodology. The linear correlation plots (Figure 6) drawn between the predicted and observed responses showed high values of $\mathrm{R}^{2}(0.9995)$.

Table 3. Composition of the checkpoint formulations, the predicted and experimental values of response variables, and percentage prediction error.

\begin{tabular}{cccccc}
\hline & Composition & $\begin{array}{c}\text { Response } \\
\text { variable }\end{array}$ & $\begin{array}{c}\text { Experimented } \\
\text { value }\end{array}$ & Predicted value & Percentage error \\
\hline $\begin{array}{c}\text { Drug } \\
\text { loading }(\%)\end{array}$ & $\begin{array}{c}\text { Ethocel Std. 45 } \\
\text { Premium: Eudragit RL }\end{array}$ & Y1 (3Hrs) & 22.848 & 22.5 & -1.55 \\
66.21 & 100 & & & & \\
& $1.87: 1$ & Y2 (6Hrs) & 48.776 & 50 & 2.45 \\
\hline
\end{tabular}

$\mathrm{Y} 1$ and $\mathrm{Y} 2$ represent the percentage drug released at the end of 3 and 6 hours of dissolution. 


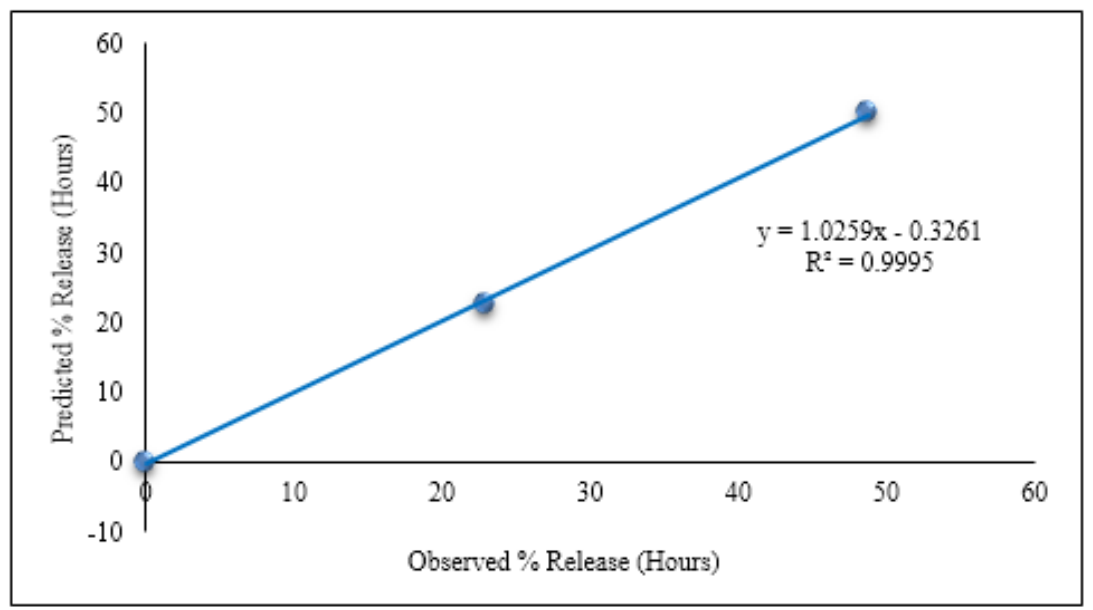

Figure 6. Predicted \% release vs. observed \% release.

Table 4. Composition of the checkpoint formulations and the experimental values of response variable.

\begin{tabular}{|c|c|c|c|}
\hline \multicolumn{2}{|c|}{ Composition } & \multirow{2}{*}{$\begin{array}{l}\text { Response } \\
\text { variable }\end{array}$} & \multirow{2}{*}{$\begin{array}{c}\text { Experimental } \\
\text { value }\end{array}$} \\
\hline $\begin{array}{c}\text { Drug loading } \\
(\%)\end{array}$ & $\begin{array}{l}\text { Ethocel Std. } 45 \text { Premium: } \\
\text { Eudragit RL } 100\end{array}$ & & \\
\hline 23.79 & 2.31: 1 & MDT (Hours) & 160.61 \\
\hline
\end{tabular}

High degree of prognosis obtained using RSM corroborates that a 2 -factor CCD is quite efficient in optimizing drug delivery systems. Both the formulation variables studied exerted a significant influence on the drug release, which was confirmed by ANOVA data. An optimized formulation with desirable release properties was developed employing numerical optimization technique. Optimum formulation showed a maximum error of $2.45 \%$ which is acceptable. Thus, it can be concluded that the response surface analysis has a reasonable power of prediction within the experimental design range.

\section{Conclusion}

Controlled release microspheres of carbamazepine were prepared and optimized successfully using response surface methodology (RSM). The results obtained indicate that response surface methodology can be employed successfully to quantify the effect of several formulation and processing variables thereby minimizing the number of experimental trials and cutting down the formulation development cost. Good correlation between the predicted responses and observed responses of the optimized formulation indicated high degree of prognosis. Results of drug release profile showed that microspheres with greater proportion of Eudragit RL 100 had rapid carbamazepine release profile. So it can be concluded that to obtain better release profile Eudragit RL 100 could be a better option.

\section{References}

Behera, B., Sahoo, S., Dhal, S., Barik, B. and Gupta, B. 2008. Characterization of glipizide-loaded polymethacrylate microspheres prepared by an emulsion solvent evaporation method. Trop. J. Pharm. Res. 7, 879-885.

Bezerra, M., Santelli, R., Oliveira, E., Villar, L. and Escaleira, L. 2008. Response surface methodology (RSM) as a tool for optimization in analytical chemistry. Talanta. 76, 965-977.

Filipović-Grčić, J., Perissutti, B., Moneghini, M., Voinovich, D., Martinac, A. and Jalšenjak, I. 2003. Spray-dried carbamazepine-loaded chitosan and HPMC microspheres: Preparation and characterization. $J$. Pharma. Pharmacol. 55, 921-931.

Gavini, E., Hegge, A., Rassu, G., Sanna, V., Testa, C. and Pirisino, G. 2006. Nasal administration of carbamazepine using chitosan microspheres: In vitro/in vivo studies. Int. J. Pharmaceutics 307, 9-15. 
Goodman, L., Gilman, A., Brunton, L., Lazo, J. and Parker, K. 2006. Goodman \& Gilman's the Pharmacological Basis of Therapeutics. McGraw-Hill, New York. 11th ed.

Haznedar, S. and Dortunç, B. 2004. Preparation and in-vitro evaluation of Eudragit microspheres containing acetazolamide. Int. J. Pharmaceutics 269, 131-140.

Jain, S., Srinath, M.S., Reddy, S.N. and Sindhu, A. 2010. Development of a floating dosage form of ranitidine hydrochloride by statistical optimization technique. $J$. Young Pharm. 2, 342-349.

Javadzadeh, Y., Jafari-Navimipour, B. and Nokhodchi, A. 2007. Liquisolid technique for dissolution rate enhancement of a high dose water-insoluble drug (carbamazepine). Int. J. Pharmaceutics 341, 26-34.

Katzhendler, I., Azoury, R. and Friedman, M. 1998. Crystalline properties of carbamazepine in sustained release hydrophilic matrix tablets based on hydroxypropyl methylcellulose. J. Contr. Rel. 54, 69-85.

Katzung, B.G. and Masters, S.B. 2015. Basic and Clinical Pharmacology. McGraw-Hill Professional, New York. $13^{\text {th }}$ ed. pp. 405-406.

Kusum Devi, V., Saisivam, S., Maria, G. and Deepti, P. 2003. Design and evaluation of matrix diffusion controlled transdermal patches of verapamil hydrochloride. Drug Develop. Indus. Pharm. 29, 495-503.

Mandal, U., Gowda, V., Ghosh, A., Selvan, S., Soloman, S. and Pal, T.K. 2007. Formulation and optimization of sustained release matrix tablet of metformin $\mathrm{HCl} 500 \mathrm{mg}$ using response surface methodology. Yakugaku Zasshi J. Pharm. Soc. Japan 127, 1281-1290.

Mane, R.B., Bhingare, C.L. and Bhalekar, M.R. 2013. Preparation and evaluation of carvedilol microsphere by spray drying technique: Effect of process parameters on formulation. Int. J. Pharm. Qua. Assur. 4, 4-12.

Moneghini, M., Kikic, I., Voinovich, D., Perissutti, B. and Filipović-Grčić, J. 2001. Processing of carbamazepinePEG 4000 solid dispersions with supercritical carbon dioxide: Preparation, characterization, and in vitro dissolution. Int. J. Pharmaceutics 222, 129-138.

Montgomery and Douglas, C. 2012. Design and Analysis of Experiments. Wiley, New York. 8th ed.
Mukhopadhyay, H.K., Das, S.K., Bhowmik, M., Ray, S., Rajabalaya, R., Ghosh, L. and Gupta, B.K. 2014. Preparation and characterization of polymethacrylatebased matrix microspheres of carbamazepine using solvent evaporation method. Farmacia 62, 137-158.

Myers, R., Montgomery, D. and Anderson-Cook, C. 2016. Response surface methodology. John Wiley \& Sons. 3rd ed.

Olling, M., Mensinga, T., Barends, D., Groen, C., Lake, O. and Meulenbelt, J. 1999. Bioavailability of carbamazepine from four different products and the occurrence of side effects. Biopharm. Drug Dispos. 20, 19-28.

Passerini, N., Perissutti, B., Moneghini, M., Voinovich, D., Albertini, B. and Cavallari, C. 2002. Characterization of carbamazepine-gelucire50/13 microparticles prepared by a spray-congealing process using ultrasounds. J. Pharm. Sci. 91, 699-707.

Rajkumar, M. and Bhise, S.B. 2010. Carbamazepine-loaded porous microspheres for short-term sustained drug delivery. J. Young Pharm. 2, 7-14.

Shivakumar, H.N., Desai, B.G. and Deshmukh, G. 2008. Design and optimization of diclofenac sodium controlled release solid dispersions by response surface methodology. Indian J. Pharm. Sci. 70, 22-30.

Singh, B., Bhatowa, R., Tripathi, C.B. and Kapil, R. 2011. Developing micro/nanoparticulate drug delivery systems using design of experiments. Int. J. Pharm. Investig. 1, 75-87.

Singh, B., Chakkal, S. and Ahuja, N. 2006. Formulation and optimization of controlled release mucoadhesive tablets of atenolol using response surface methodology. AAPS Pharm. Sci. Tech. 7, 1-10.

Sonje, A. and Chandra, A. 2013. Comprehensive review on Eudragit polymers. Int. Res. J. Pharm. 4, 71-74.

USP 29, United States Pharmacopoeia 29. 2007. The United States Pharmacopoeial Convention. 